\title{
INTERVENCIÓN DE CONSERVACIÓN Y RESTAURACIÓN DE UN ARCA DE NOVIA CATALANA DEL SIGLO XVI
}

\author{
CONSERVATION AND RESTORATION INTERVENTION OF A 16TH CENTURY \\ CATALAN BRIDAL CHEST
}

Josep Paret Pey*

Jesús Zornoza Esteban**

Centre de Restauració de Béns Mobles de Catalunya

\section{Resumen}

El Centre de Restauració de Béns Mobles de Catalunya (CRBMC) ha realizado la conservación y restauración de un cofre de novia catalán de madera policromada. Antes de la intervención se realizó un completo estudio preliminar. Este estudio comienza con un análisis fotográfico con diferentes tipos de iluminación: luz visible (luz difusa aplicada de diferentes formas, con más o menos detalle y luz rasante) y radiación invisible (luz ultravioleta e infrarroja), para finalizar con la radiografía. Estas técnicas de examen se complementan con análisis fisicoquímicos, que permiten obtener información específica sobre sus materiales constituyentes.

Finalmente, se trata de poner estos análisis a disposición de los conservadores para profundizar en el conocimiento de la obra y poder hacer una mejor propuesta de conservación y restauración. De la misma forma, puede ser útil para los historiadores del arte para determinar atribuciones, fechas o identificar la veracidad o falsedad de las mismas.

Palabras clave: Arcón, escudos, policromía, mueble, técnicas de examen, estudio técnico-científico

\section{Abstract}

The Centre de Restauració de Béns Mobles de Catalunya (CRBMC) has enabled the conservation and restoration of a Catalan polychrome wooden bridal chest. Before the intervention a complete preliminary study was carried out. This study begins with a photographic analysis with different types of lighting: visible light (diffuse light applied in different ways, with more or less detail and raking light) and invisible radiation (ultraviolet and infrared light), to end with the X-ray. These examination techniques are complemented by physicochemical analyses, which allow obtaining specific information on its constituent materials.

Finally, it is about making these analyses available to the conservators to deepen their understanding of the work and to be able to make a better conservation and restoration proposal. In the same way, it can be useful for art 
historians to determine attributions, dates or identify the veracity or falsity of them.

Keywords: Chest, shields, polychrome, furniture, examination techniques, technical-scientific study

\section{Ficha técnica:}

Núm. registro CRBMC: 13803

Núm. registro PALAU GENERALITAT: 227781

CLASSIFICACIÓN GENÉRICA: mueble

OBJECTO: arca de novia

MATERIAL / TÉCNICA: madera, pintura al temple, talla, dorado

TÍTULO / TEMA: arca de novia con escena de la Anunciación

AUTOR: Indeterminado

DATA / ÉPOCA: siglo XVI

DIMENSIONS: $74,5 \times 136 \times 59 \mathrm{~cm}$

PROCEDENCIA: desconocida

LOCALIZACIÓN: Sala dels Diputats, Palau de la Generalitat, Barcelona

El arca o arcón entendido como un cajón con tapa abatible es un mueble simple utilizado en algunas culturas con el fin de guardar y conservar todo tipo de bienes desde alimentos, objetos, dinero, enseres, ropas y objetos personales. En el siglo XV y XVI se generaliza el uso del arca: en ese momento existen en los interiores domésticos pocos contenedores donde guardar objetos y el arca es el mueble más utilizado.

En Catalunya el arca tradicional deriva hacia un mueble ricamente decorado con el uso de molduras, talla, policromía y oro, utilizando similares patrones estilísticos a lo largo de su evolución. Su forma constructiva se mantiene inalterable desde finales del siglo XV hasta el siglo XVIII, momento en el cual se produce una lenta sustitución por la cómoda.

El modelo propio de Catalunya evoluciona al final del siglo XV incorporando una puerta en el panel derecho donde se encuentran tres cajones escondidos y una gaveta, normalmente con los frontales ricamente decorados del mismo modo que el interior de la puerta. Posteriormente, ya en el siglo XVI algunas arcas incorporan un cajón escondido en el zócalo inferior.

"A medida que transcurre el siglo se abandonan los motivos de cuadrados girados inscritos en los paneles, siendo sustituidos por motivos pintados, lo cual permitirá articular una decoración más rica, con cierta variedad de repertorios. El más habitual consistirá en motivos heráldicos..."1. Además de estos escudos podemos encontrar, algunas veces, retratos pertenecientes a los contrayentes. No obstante, un arca con dos escudos familiares diferentes, no tiene que ser obligatoriamente señal de propiedad compartida, ya que podría tratarse de los dos escudos de los progenitores de uno de los esposos o de sus dos apellidos.

Normalmente este tipo de arca es el ajuar que la novia aporta como dote, a veces dos arcas si la familia tenía un mayor poder adquisitivo. No obstante, 
es sabido que no todas las cajas con cajones tenían que formar parte de la dote, y también que no todas las mujeres podían aportar al noviazgo este modelo de contenedor. En general, "La documentación revela que en su interior se guarda la ropa de la novia y la de la boda, que ella mantendrá en su propiedad a lo largo del tiempo. En caso de fallecimiento del marido observamos como ella las recupera, junto al resto de bienes aportados en dote al matrimonio." ${ }^{2}$

En cuanto a la decoración de la tapa el recurso estilístico normalmente se basa en composiciones religiosas de repertorios de la vida de la Virgen: Anunciación, Nacimiento, Adoración o relativas a la vida de otros santos.

"Cabe destacar que hubo principalmente dos tipos de cajas, las de dos paneles separados por montantes moldurados-medio cofre-, y las de tres paneles o cofre mayor; creemos que las dimensiones del interior de estas últimas rondaban la cana, medida que en Barcelona equivalía a $156 \mathrm{~cm} .{ }^{3}$

Se tiene noticia que Barcelona fue un centro importante en la elaboración de arcas policromadas, como también el Vallés, Osona, Maresme, el Bages, Anoia y Tarragona, así como el reino de Valencia.

En la actualidad, se pueden ver algunas arcas policromadas en numerosos museos de Catalunya. Este tipo de mobiliario tuvo gran revalorización a final del siglo XIX, momento en el que muchas de estas arcas se repolicromaron o se intervinieron sin seguir los actuales criterios técnicos de restauración.

\section{El arca del Palau de la Generalitat}

La caixa de núvia o arca de novia en castellano se encuentra en el Palau de la Generalitat de Catalunya, sede de la Presidencia de la Generalitat de Catalunya. Está ubicada en la sala dels Diputats en la planta noble del edificio gótico del palacio. Desgraciadamente no se conocen datos de la incorporación de esta pieza al Palau de la Generalitat, ni de los antiguos propietarios.

El mueble motivo de estudio es un arca con cajones, tipología que tradicionalmente, la historiografía ha nombrado caixa de núvia o arca de novia, aunque no es un término utilizado en la documentación de la época. Se tiene constancia que una gran parte de estas arcas con cajones formaban parte de las dotes de las mujeres de familias acomodadas, en ocasiones, una, a menudo dos o incluso más, con su ropa y pertenencias personales aparte del dinero, como aportación al matrimonio, de ahí su nombre. Pero no era exclusivo de las mujeres, también los hombres podían disponer de arcas con cajones para la necesidad de guardar y clasificar mejor sus pertenencias personales. En nuestro caso, sin ninguna documentación que ayude a informar del propietario, no es posible saber si pertenecía a un hombre o a una mujer.

Estamos delante de un arca que datamos entre 1525 y 1540. Aunque la estructura del cajón sigue modelos de finales del siglo XV, la policromía nos lleva a retardar su factura. No es nada extraño este hecho en muebles que conservan formas y estructuras arcaicas en muebles con motivos decorativos más modernos. ${ }^{4}$ 


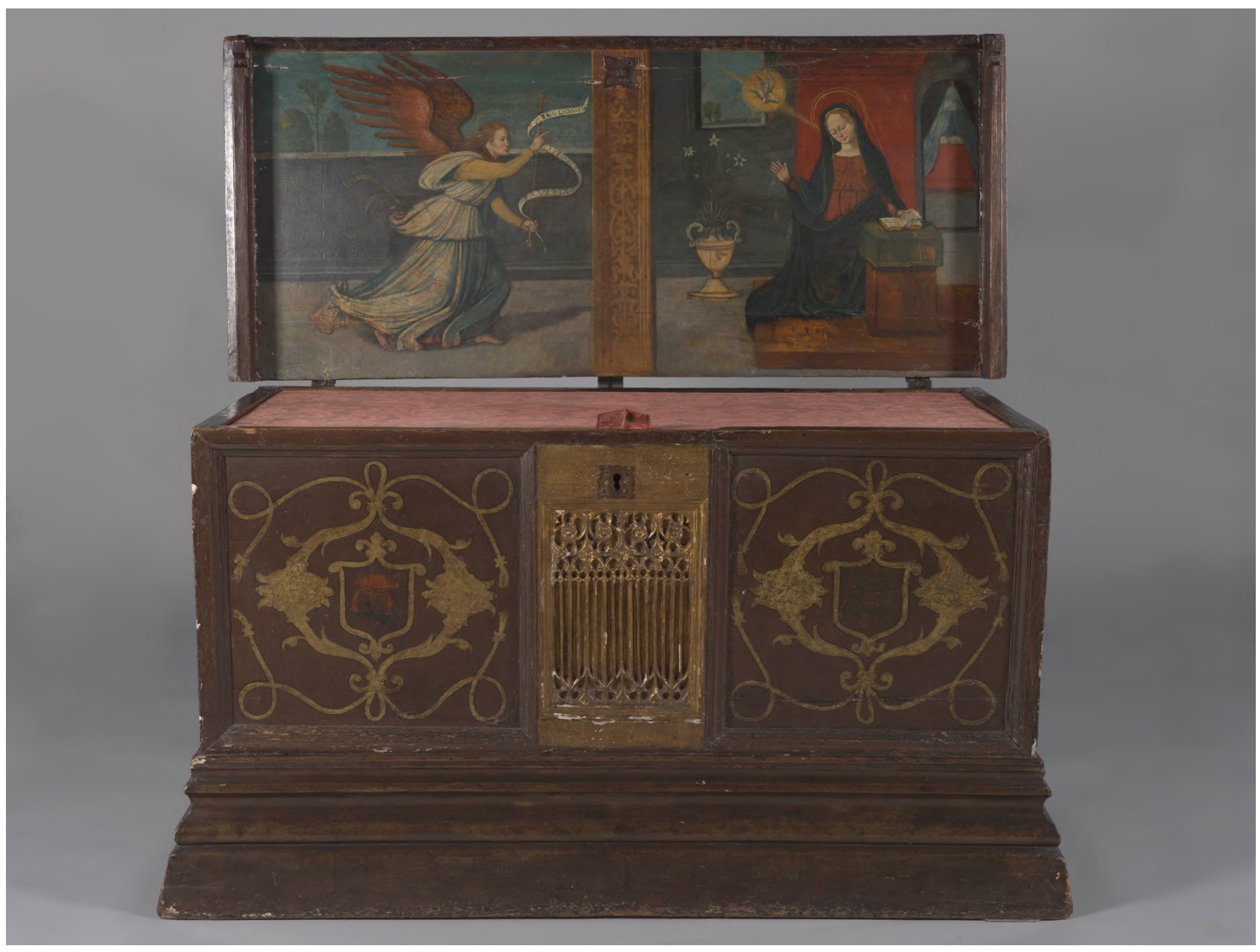

Foto 1: Vista general antes de la intervención de conservación y restauración

\section{Estudio histórico y formal}

Caja de madera de álamo (populus) formado por cuatro tableros unidos entre sí por colas de milano; el tablón del fondo está clavado a la caja mediante clavos de forja. Un faldón o zócalo moldurado también clavado con clavos de forja circunda las tres caras externas del arca. La parte trasera no presenta zócalo. En el frontal se hallan paneles moldurados separados por un montante tallado en madera. La parte superior tiene la tapa abatible plana con dos listones y guardapolvos en los extremos; la tapa está sujeta con bisagras.

Todo el exterior y el zócalo de la caja está policromado, pintado en color marrón sobre una base de color rojizo tipo bol. Sobre esta capa hay una decoración de escudos que se van repitiendo intercalados; encontramos un escudo con ramas verdes entrecruzadas y otro con un birrete eclesiástico y un lobo. Los escudos están ornamentados en su perímetro con decoración vegetal y con cintas con borlas. Desgraciadamente, nada de esta capa pictórica es original, ya que se trata de una repolicromia.

La presencia de un escudo eclesiástico presupone, según la experta en heráldica Leticia Darna, que la caja debe ser por lo menos del siglo XV o XVI, ya que antes de estas fechas no existían los timbres de los obispos. Una posibilidad es que fuera de la época posterior a Adriano de Utrecht (1459-1523), que concedió a los obispos de Tortosa el privilegio de pintar el birrete como los cardenales, aunque no se ha encontrada alrededor de esa fecha ningún prelado que lleve 
como emblema familiar un lobo. Una posible explicación es que podría tratarse de un añadido posterior realizado por manos poco expertas. Otro dato a tener en cuenta es que los lobos son muy propios de la heráldica vasca, aunque tampoco se sabe de ningún obispo que llevase ese emblema, únicamente.

En cuanto al otro dibujo de unas cruces potenzadas entrelazadas, tampoco se ha podido reconocer a la familia a la que pertenecen, ni tampoco tenemos constancia que pertenezcan a ninguna orden religiosa.

Los plafones centrales de la caja quedan separados por un montante de tracería gótica con hojas de oro bruñido y decoración en retícula romboidal con incisiones de cincelado.

El interior de la tapa está pintado con la escena de la Anunciación. La Anunciación de la tapa presenta, pese a su sencillez compositiva, un estilo renacentista. La escena queda dividida en dos mitades por una cenefa-que integra la cerradura- con motivos a candelieri de diseño muy sencillo, enmarcados por dos bandas acanaladas que sugieren pilastras. María se sitúa a la derecha de la composición, cubierta por un baldaquino rojo que subraya su protagonismo y arrodillada sobre un estrado de madera, delante de un pequeño reclinatorio donde reposa un libro abierto. Al fondo un arco de medio punto da paso al dormitorio de la Virgen, con una cama cubierta por un segundo baldaquino, en este caso de formato cónico. Una pequeña ventana permite la entrada de la paloma del Espíritu Santo, inscrito en una aureola dorada. A la izquierda de la composición se percibe un muro bajo, por encima del cual se vislumbran las copas de algunos árboles, sugiere la existencia de un pórtico delante de las estancias de María. Es aquí donde acaba de descender el mensajero angélico, con los ropajes aun ondeando y las alas desplegadas. Gabriel se dirige con un elocuente gesto hacia la Virgen, enarbolando en la mano izquierda un cetro alrededor del cual se envuelve una filacteria con las palabras "AVE MARIA GRACIA PLENA DOMI” (Lucas1, 28) ${ }^{5}$.

\section{Estudio preliminar, examen organoléptico}

Se observa, a simple vista, que el arca ha sido muy manipulada y que ha sufrido varias intervenciones y repolicromías. Es difícil conocer y entender con un examen simplemente ocular las secuencias pictóricas y a la vez evaluar el estado original.

Para ello, recurrimos a diversas técnicas de examen y a análisis fisicoquímicos que han sido realizados por los diferentes técnicos del Centre de Restauració de Béns Mobles de la Generalitat de Catalunya (CRBMC). Por otro lado, a nivel histórico, contamos con el estudio razonado encargado a la Associació per a l'Estudi del Moble.

La pieza ha estado documentada fotográficamente en las diversas etapas del proceso de conservación-restauración y ha estado sometida a diferentes técnicas de examen con diversos sistemas de iluminación aplicados a la fotografía, así como con técnicas fotográficas basadas en diferentes radiaciones (IR i UV) que, juntamente con la radiografía, forman un amplio abanico de posibilidades para conocer materialmente la obra. Estas técnicas de examen han sido complementadas con los análisis fisicoquímicos que se han llevado a cabo en el 
laboratorio del CRBMC. Estos análisis están destinados a determinar la naturaleza de los materiales constitutivos de la obra, caracterizar productos añadidos en intervenciones anteriores y caracterizar productos de alteración y/o de envejecimiento.

\section{Estudio con técnicas fotográficas:}

\section{Radiaciones UV}

Nos permite examinar la obra de arte y sus intervenciones en las capas más externas. Esta técnica nos facilita visualizar las intervenciones de retoques i repintes, a nivel cromático, y otras alteraciones gracias a la diferencia de absorción y fluorescencia de los materiales utilizados originales y modificaciones. Podemos observar, además de repintes y retoques, alteraciones de la capa de barniz u otras trasformaciones. Esta técnica nos ha dado a conocer intervenciones anteriores y nos ha ayudado a valorar posteriores metodologías de trabajo y de actuación y nos permite determinar con mayor claridad las zonas que queremos analizar.

El estudio del arca a través de las radiaciones UV nos ha permitido identificar sobre todo la última secuencia o intervención de repintes de la escena de la Anunciación. Hemos podido cuantificar las zonas repintadas y valorar la posible eliminación. Muchas de ellas no sólo tapaban las antiguas zonas pérdidas, sino que cubrían grandes partes de la pintura original. En cuanto a la policromía de la parte externa de la caja la luz ultravioleta y la radiación IR nos han proporcionado poca información.

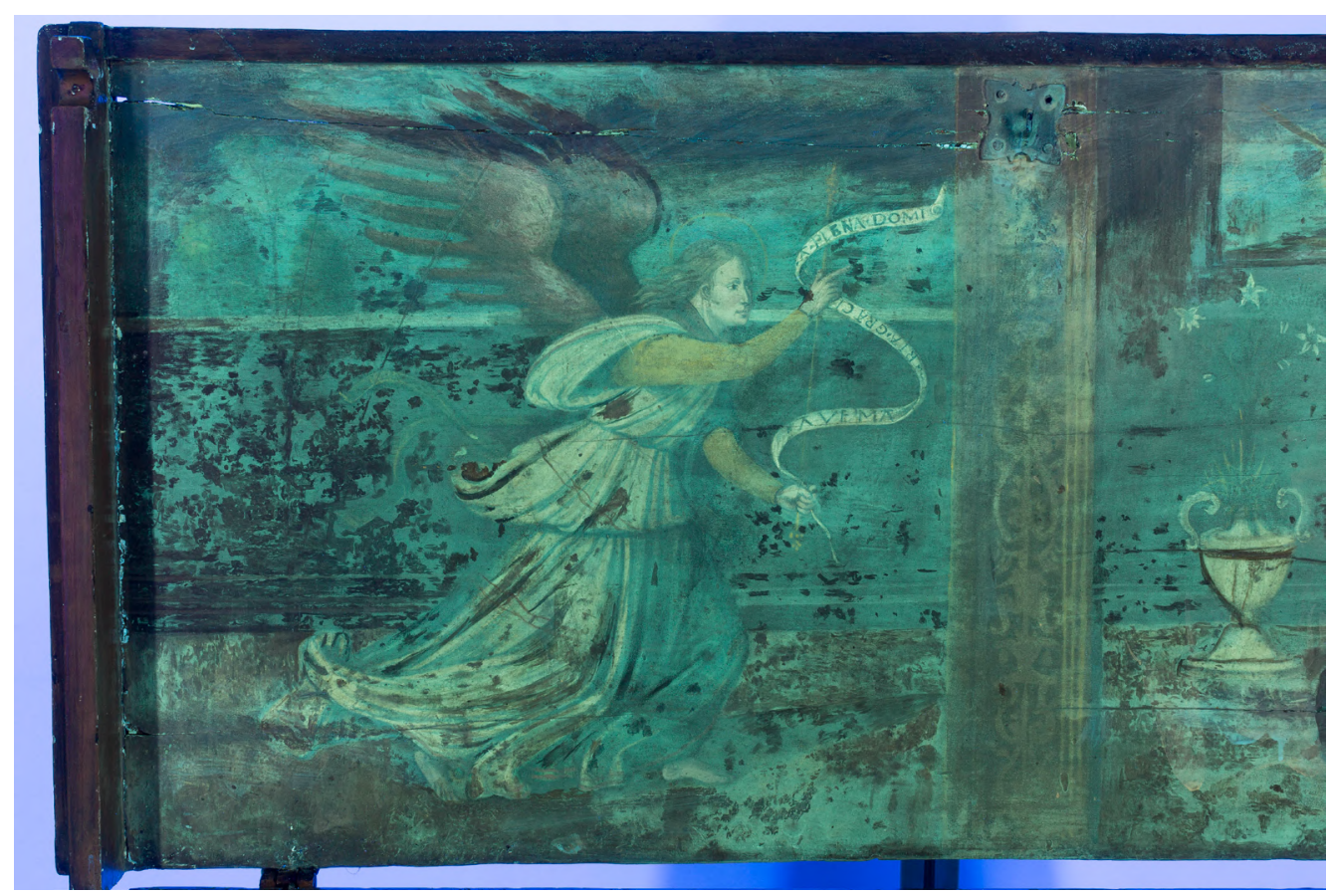

Foto 2: Detalle escena de la Anunciación: Arcángel vista con luz ultravioleta 


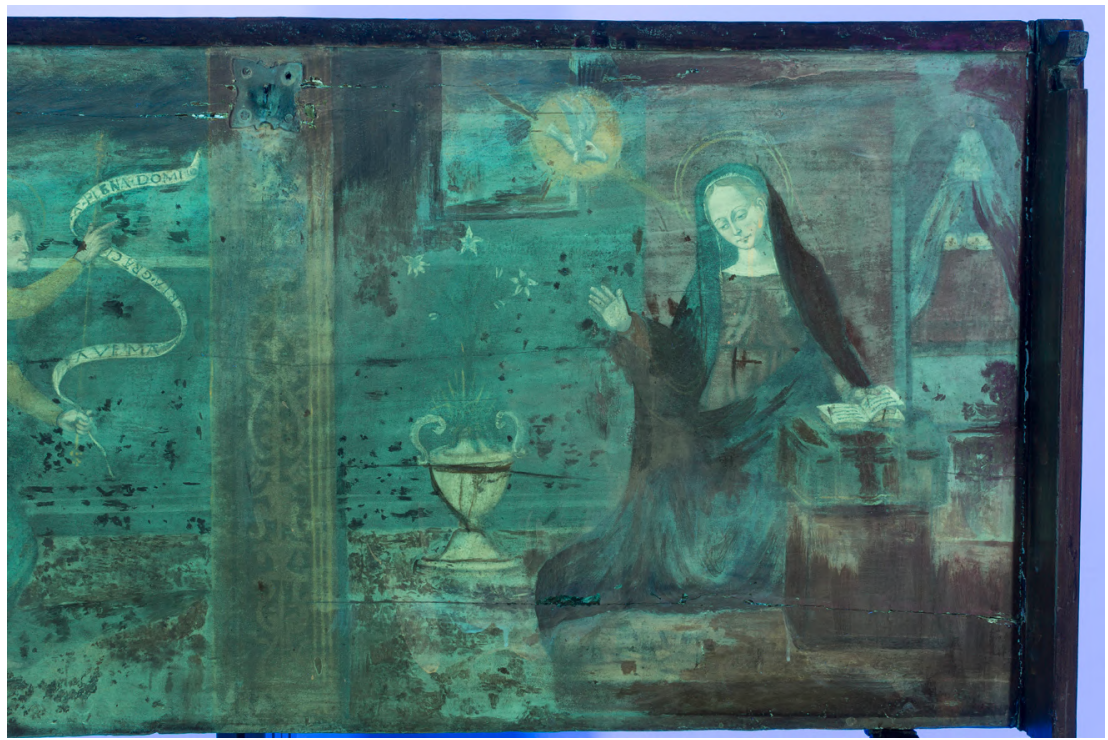

Foto 3: Detalle escena de la Anunciación: Virgen María vista con luz ultravioleta

\section{Radiación IR:}

Esta radiación no visible nos permite atravesar en profundidad la capa pictórica y nos ofrece conocer la existencia de capas de dibujo preparatorio, arrepentimientos o intervenciones anteriores y nos ayuda a delimitar claramente zonas de pérdidas de capas de preparación y pictórica, así como repintes.

La fotografía IR. en el estudio de la tabla de la Anunciación nos ha permitido conocer una restauración más antigua oculta a simple vista que se encuentra debajo de los repintes mucho más invasivos y modernos (1969, visibles con la fotografía UV). Por otro lado, no se observa con claridad el dibujo preparatorio ni se observan arrepentimientos. El resto de la capa pictórica de la caja no ofrece más información.

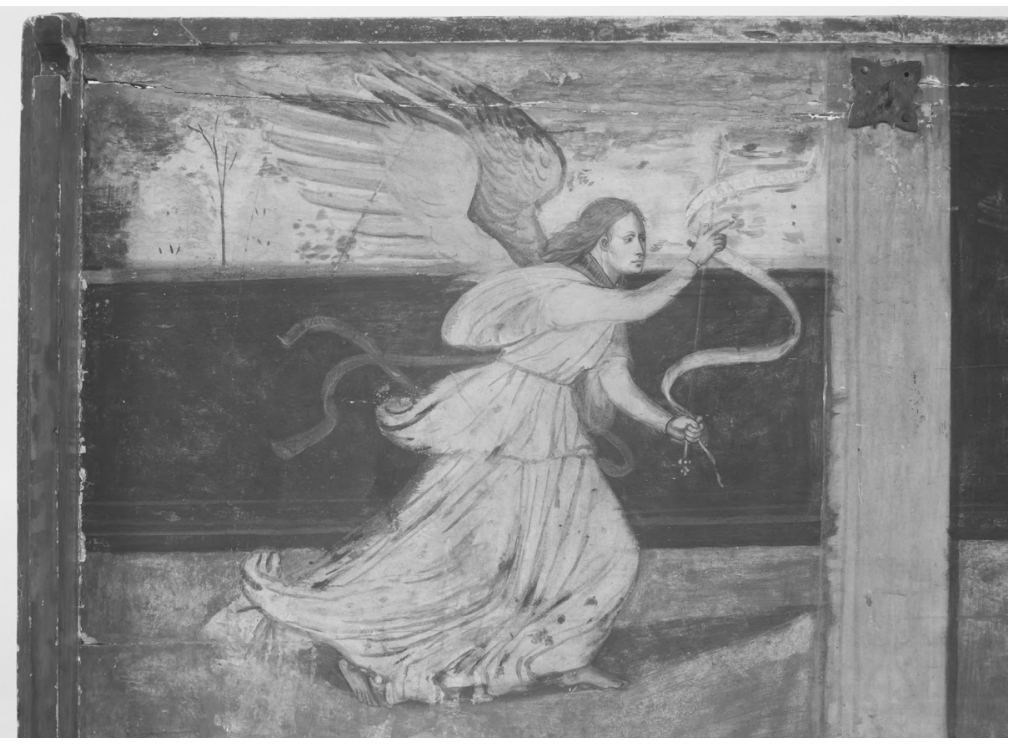

Foto 4: Detalle escena de la Anunciación: Arcángel vista con luz infrarroja 


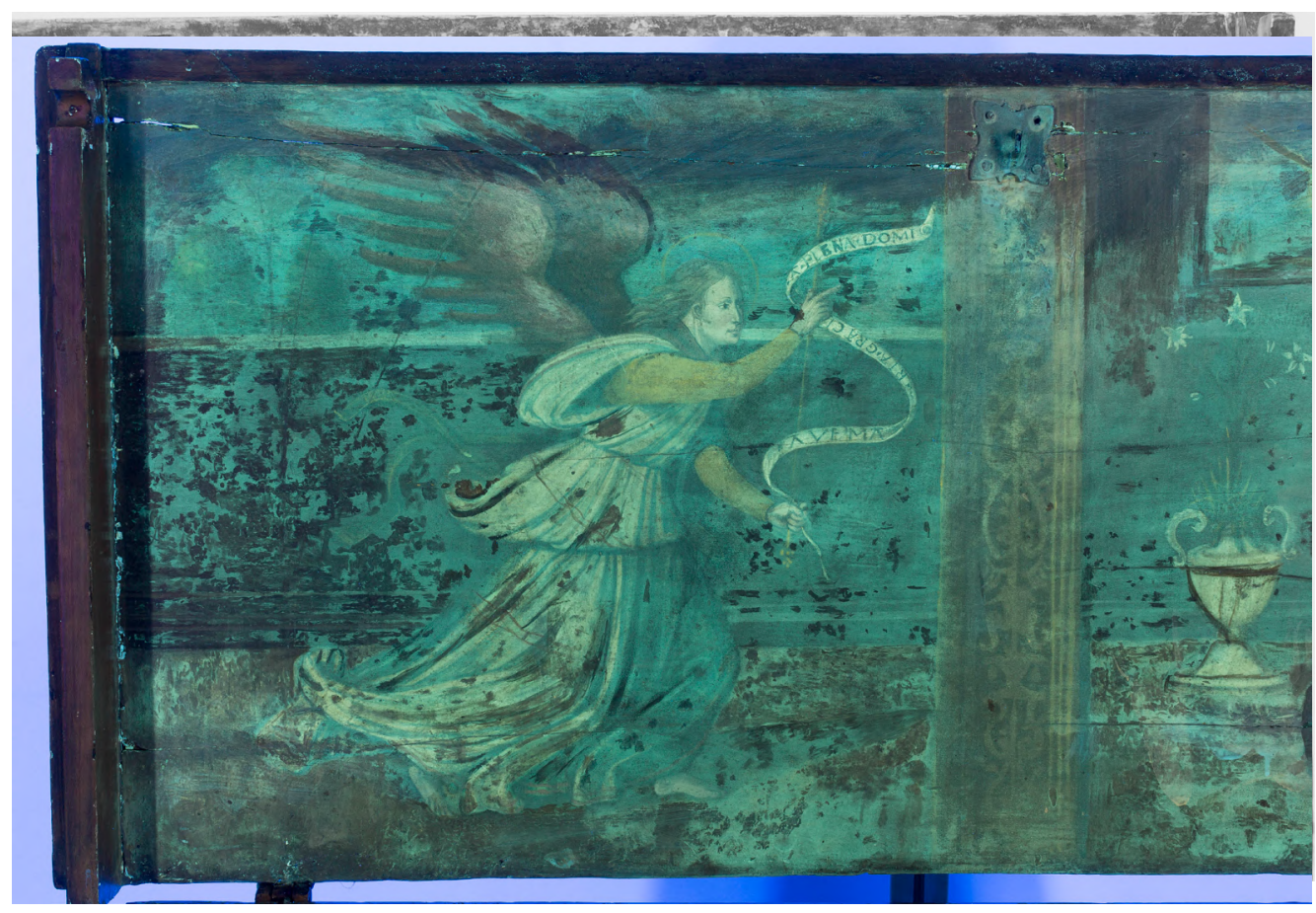

Foto 5: Detalle escena de la Anunciación: Virgen María vista con luz infrarroja

\section{Radiografía:}

La radiografía nos permite la visión de la estructura interna de las obras: conocimiento de las técnicas de fabricación, modificaciones anteriores, identificación de maderas, tipos de uniones (número de elementos, espigas, clavos, elementos metálicos, etc.), la visualización de elementos añadidos, la determinación de la magnitud del ataque de los insectos xilófagos, la delimitación precisa de las lagunas de la policromía, capas de preparación particulares con inclusión de tela o estopa, etc.

Utilizando las técnicas radiológicas hemos podido reconocer los métodos constructivos y posteriores intervenciones gracias a la identificación de los clavos originales de forja y los clavos industriales modernos, así como reconocer las uniones, ensamblajes, molduras, cerradura, así como visualizar las galerías de los insectos xilófagos.

\section{Análisis fisicoquímicos}

En paralelo y durante el proceso de restauración se han tomado 22 muestras de madera, pigmentos, aglutinantes y barnices. Las analíticas se han realizado mediante diferentes técnicas: microscopía estereoscópica, microscopía óptica, espectrofotómetro FTIR y microscopía electrónica de rastreo microscopio SEM-EDX.

Estas muestras nos han ayudado a profundizar en el conocimiento de la obra y a clarificar algunas dudas planteadas durante el estudio y proceso de restauración.

En un primer lugar, nos han confirmado los materiales originales que se utilizaron y hemos podido cotejar similitud entre pigmentos originales entre 
la tapa y la caja, que en un primer momento nos parecían elementos aprovechados de diferentes muebles. Además, hemos podido conocer y profundizar en los materiales utilizados en intervenciones que ha sufrido la pieza a lo largo de su historia.

Se puede concluir que la madera de la tapa y de la caja es de populus sp., álamo, muy utilizada como material de soporte de arcas y retablos en Catalunya.

La capa pictórica de la tapa tiene una preparación compuesta de sulfato cálcico y aglutinada con una sustancia proteica. Los pigmentos también están aglutinados también con una sustancia proteica (cola animal).

En la capa de superficie encontramos un barniz nitrocelulósico moderno y sobre la capa pictórica de la Anunciación hallamos una resina natural diterpénica de colofonia.

En varias muestras se observa la presencia de cera intercalada entre las capas pictóricas. La cera es el material utilizado para la fijación de los estratos pictóricos en las intervenciones anteriores y se puede observar a simple vista donde se ha aplicado como relleno de grietas y agujeros.

El interior de los escudos está repintado. Se observa que el lobo o las cuatro barras entrecruzadas están por debajo del nivel del resto de la policromía. Lo mismo sucede con las decoraciones vegetales que contornean los escudos. De entrada, todo indica que hubo una alteración que degradó algunos de los materiales, quedando sólo una plantilla, silueta o depresión en la capa pictórica, que a posteriori repolicromaron (en la primera intervención) junto al resto de la caja. Gracias al examen exhaustivo de la pintura solamente hemos encontrado unas pequeñas partículas en el escudo que nos indican la utilización de aleación de plata-oro sobre una sustancia proteica sin una capa de bol, ésta es, según parece, la causa de la pérdida generalizada del dorado. Según estos resultados, podemos extrapolar la misma alteración al resto de las zonas bajo nivel.

En las estratigrafías de los escudos se observa que están repintados: se puede ver que bajo la capa marrón existe otra de color azul. Este azul índigo es el mismo que el utilizado en los azules de la tabla.

\section{Intervenciones anteriores en el arca}

Tras evaluar el estado de conservación creemos que podemos identificar dos grandes intervenciones: la primera muy invasiva y poco rigurosa, desde el punto de vista actual de la conservación-restauración. Además, conjeturamos que anteriormente el arca podría presentar un estado ruinoso. Esa actuación sin datar, pero realizada en época moderna, probablemente coincida con la revalorización de muebles góticos o renacentistas a partir del final del siglo XIX que normalmente encontramos muy intervenidos. Hay muchos ejemplos en la colección del Museu del Disseny de Barcelona y restauradas en el CRBMC.

En esta intervención se reflejan los grandes cambios que ha sufrido el arca: sustitución de molduras y reparaciones estructurales en la parte inferior reforzadas con ménsulas y listones. A esa época correspondería la pérdida y eliminación de la estructura y de los tres cajones del interior; también la eliminación de la función de la puerta del cuadrante derecho, bloqueándola con colas de milano desde el interior. Se minimiza la visión de la puerta, sellando sus 
uniones, así como las guías de los cajones, y se ocultan todas las irregularidades e intervenciones en el soporte de madera con estuco.

Por lo que se refiere a la tapa, se colocaron dos listones de madera de pino en los extremos con dos guardapolvos. Es interesante remarcar la utilización de las primeras bisagras originales de anillas y su sustitución por otras bisagras también desaparecidas, que fueron renovadas por unas terceras colocadas desde el exterior, que son las que vemos en la actualidad.

Otra pérdida importante la encontramos en el interior de la puerta, seguramente decorada originalmente con tracerías góticas doradas similares a las del registro central del frente, el montante o monjo del exterior. Bajo un examen ocular podemos intuir unas ligeras huellas que ha dejado esta tracería perdida. Es habitual encontrar decoraciones con motivos de tracerías similares en el interior de la puerta y en el frontal de los cajones. Otro elemento perdido es la pequeña pieza calada del fondo del arca que tenía una función de ventilación y respiradero.

Seguramente también de aquel momento corresponde la repolicromía de toda la caja del arca, repintada de color marrón, repintando los escudos y el resto de las decoraciones.

Tenemos documentada otra gran intervención fechada en 1969 gracias a una factura. Los trabajos son de Ramón Gudiol y en ella se explican de una manera muy general los procesos de restauración. Según dicha factura, los trabajos de esta restauración han comprendido: limpieza total de la parte pintada, asentar parte del colorido que se desprendía del soporte, reforzar la madera y reajustar las partes agrietadas, y, finalmente, restaurar los fragmentos perdidos de pintura y de talla doradas.

De esa intervención seguramente datan los repintes en la caja de color marrón oscuro que cubren sobre todo las molduras y zócalo gastado, las masillas para minimizar irregularidades, así como las zonas repintadas de la Anunciación y que se observan perfectamente con la luz ultravioleta.

La capa pictórica de la tapa está muy gastada, se han perdido muchas veladuras por abrasión (seguramente por las limpiezas excesivas). Esto hace que la pintura haya perdido trazos que le darían mayor delicadeza; aunque se aprecian detalles pictóricos de mayor calidad como pueden ser las caras, no sucede los mismo con el tratamiento de las manos u otros elementos. Por lo tanto, podríamos deducir que dos artistas participan en la ejecución de la pintura.

\section{Criterios de restauración}

Toda intervención se rige por unos criterios de intervención aplicados a la conservación y restauración de bienes culturales.

Desde que la conservación de bienes culturales se configura como una disciplina científica, los principios teóricos y las pautas metodológicas avanzadas por las diferentes escuelas de pensamiento se han intentado compendiar en instrumentos de caracteres y marcos de aplicación diversos: convenciones, cartas de restauración (...) los cuales se han ido determinando en reuniones y congresos internacionales, muchos de los cuales patrocinados por la UNESCO.

Los criterios de intervención del CRBMC en el patrimonio mueble y en el patrimonio artístico que forma parte del patrimonio inmueble se basan en los 
que regula la ley de patrimonio cultural 9/1993 del Patrimonio cultural catalán, y muy especialmente en las cartas de restauración internacionales, principalmente la de Venecia (1964), las Cartas del Restauro (1972 y 1987) y la de Cracovia (2000).

De acuerdo con las cartas mencionadas y los criterios consensuados por las instituciones internacionales y la propia ley catalana, el CRBMC, tal y como describe en su página web, sintetiza los criterios de intervención en los siguientes:

- Mínima intervención

Hay que manipular la obra el mínimo imprescindible para no someterla a tensiones y riesgos innecesarios, y garantizar así la máxima conservación. Así mismo, se rechazan los tratamientos demasiado intervencionistas. Debe predominar la conservación sobre la restauración.

- Máximo respeto a la obra en toda su integridad

Hay que respetar los aspectos formales, materiales y estructurales de la obra. Se preservará todo lo que proporcione información sobre el proceso de elaboración de la obra de arte. Antes de eliminar cualquier agregado histórico, se estudiará el caso a fondo, documentándose en profundidad para poder valorar con rigor la decisión.

- Conocimiento de las causas de degradación

Previamente a la intervención, hay que conocer las causas que han originado el proceso de degradación de la obra. Sólo así se puede actuar de una manera adecuada. Los estudios previos se convierten siempre recomendables y muy a menudo imprescindibles.

- Legibilidad

Preservar el mensaje estético de la obra, sin crear un falso histórico. Siempre se debe poder diferenciar el original del agregado.

Concretamente la ley 3/1993 del patrimonio cultural dice en su artículo 35.1 que está prohibido de reconstruir total o parcialmente el bien, excepto en los casos que se utilicen partes originales, y de hacer adiciones miméticas que falseen la autenticidad. También regula que es prohibido eliminar partes del bien, salvo en el caso de que comporten la degradación del bien o que la eliminación permita una mejor interpretación histórica.

- Reversibilidad

Cualquier material añadido debe poderse retirar en un momento posterior. Por ello, hay que conocer muy bien la composición de los productos que añadimos y ver su respuesta a lo largo de los años.

- Estabilidad

Los materiales empleados en la restauración deben ser compatibles con los componentes de la obra original. Se deben mantener al máximo posible inalterables en el tiempo. Hay que evitar todo tratamiento que no tenga las debidas garantías y que pueda ser causa de degradación de la obra. 
En relación a los materiales, la carta de Cracovia, por ejemplo, destaca que se ha de estimular el conocimiento de los materiales tradicionales y que, en todo caso, los materiales y las nuevas tecnologías se han de probar rigurosamente, compararlos y adecuarlos a las necesidades reales de conservación, y evaluar su comportamiento posterior y su reversibilidad. La Carta del Restauro de 1987 señala que el uso de las técnicas tradicionales no ha sido nunca excluido por las Cartas de Restauración precedentes y que, en el caso de patologías ordinarias, es siempre preferible adoptar técnicas y materiales tradicionales, que son más homogéneos con las obras que debemos preservar.

- Documentación

Antes de iniciar cualquier intervención directa hay que recoger toda la información disponible: datos técnicos, históricas, artísticas, material de anteriores intervenciones o documentación fotográfica. Tras la intervención, hay que dejar constancia de todos los detalles de la intervención, con la redacción de memorias o informes técnicos. Es muy importante la documentación fotográfica de todo el proceso.

- Interdisciplinariedad

La conservación y la restauración de los bienes culturales es un trabajo en equipo, interdisciplinario, que requiere de una metodología científica. Además del conservador-restaurador, el arquitecto, el químico o el fotógrafo, pueden intervenir historiadores del arte, arqueólogos, físicos, geólogos y biólogos, principalmente, pero también especialistas profesionales de cada uno de los campos requeridos en una intervención.

- Conservación preventiva

La conservación preventiva consiste en actuar indirectamente sobre el objeto, mediante el análisis y control de las condiciones de su entorno, a fin de evitar, en lo posible, su degradación.

Hay que crear un medio ambiente de acuerdo con las exigencias de durabilidad del objeto. Esto implica el conocimiento del comportamiento físico y químico de los materiales que componen la obra y de su entorno.

\section{Intervención de conservación-restauración:}

El proceso ha empezado por un tratamiento curativo de desinsectación del arca en cámara de anoxia, donde se sustituye el oxígeno por nitrógeno, durante un mínimo de 21 días. El nivel de oxígeno ha estado durante todo este tiempo por debajo del $0,1 \%$.

Una vez en el laboratorio, se ha empezado por una limpieza mecánica superficial del polvo y de las telarañas, sobre todo en las partes más ocultas, como el interior del zócalo.

Posteriormente, se ha procedido a retirar mecánicamente los estucos y rellenos que enmascaraban la puerta. De esta manera, aunque no se ha recuperado su apertura, si se ha potenciado de nuevo su visión. 
Para la correcta utilización de disolventes para la limpieza de las superficies pictóricas, se ha llevado a cabo el protocolo de limpieza de obras de arte del CRBMC que dispone de un conjunto de diferentes sistemas tampón o buffers que se han de utilizar según los resultados obtenidos a partir de la medición del $\mathrm{pH}$ y de la conductividad de diferentes zonas y colores de la superficie pictórica.

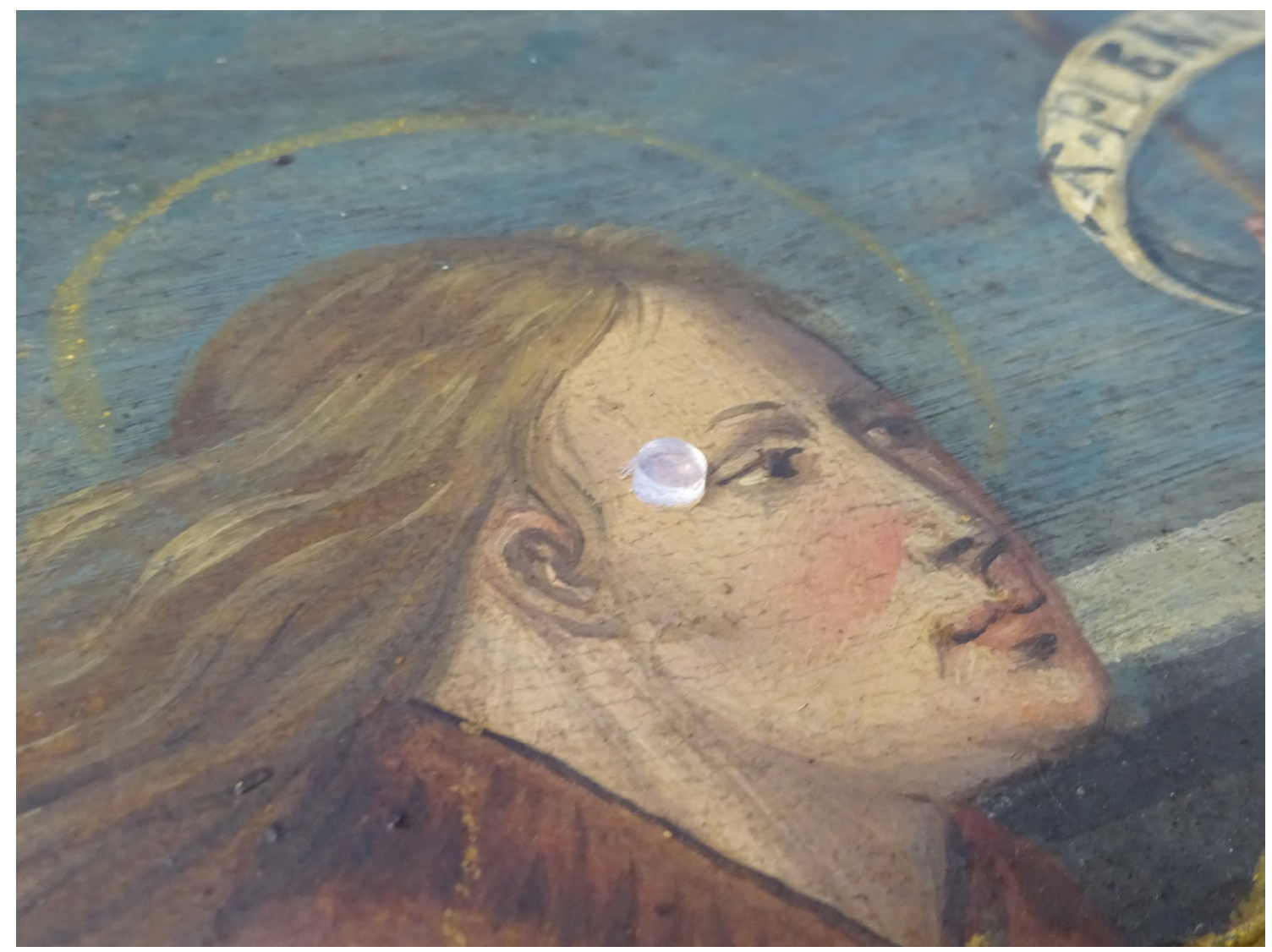

Foto 6: Medida del pH y de la conductividad de la superficie pictórica a partir de la muestra obtenida en un gel rígido

Una vez realizada la limpieza acuosa, y para la remoción de las capas de suciedad y del barniz teñido de la cara externa de la tapa, se han utilizado disolventes gelificados. De esta manera se ha recuperado su color natural. Como acabado final se han aplicado varias capas de cera natural.

La remoción o eliminación total de las capas de barniz envejecido de la superficie pictórica se hace mediante el uso de disolventes gelificados. Esta metodología de trabajo reduce la penetración y la actuación de los disolventes en las capas más internas de la pintura. A partir de la eliminación del barniz se ha podido dejar limpia la policromía y se han podido eliminar algunos repintes antiguos. 

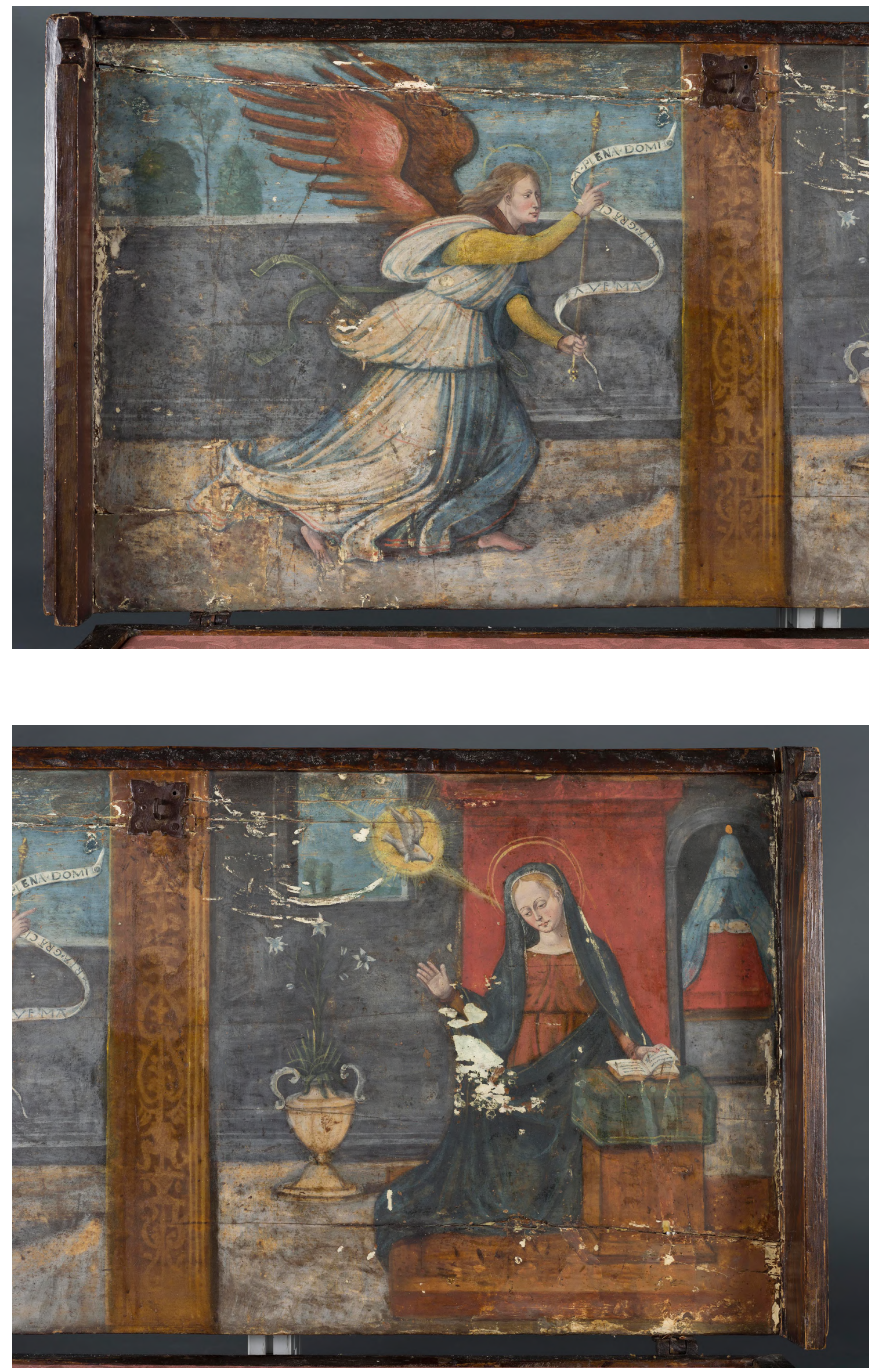

Foto 7 y 8: Superficie pictórica después de la limpieza y remoción de repintes 
Del exterior de la caja hemos eliminado los repintes marrones recientes, pero sin recuperar los fondos de la policromía original, ya que debajo de esta capa solamente se observan restos de color que podría corresponder a una capa de bol o color similar. En cambio, sí se ha podido recuperar la policromía original de los escudos. Se han eliminado los repintes pudiendo recuperar el color azul de fondo y el birrete eclesiástico repintado con el mismo color rojo. Se ha mantenido el color negro repintado sobre la figura del lobo para no desdibujar la forma, ya que no se conserva la hoja metálica original. Bajo el escudo con las ramas verdes se ha podido recuperar un motivo más perfilado perdido que no conserva la aleación de plata-oro.

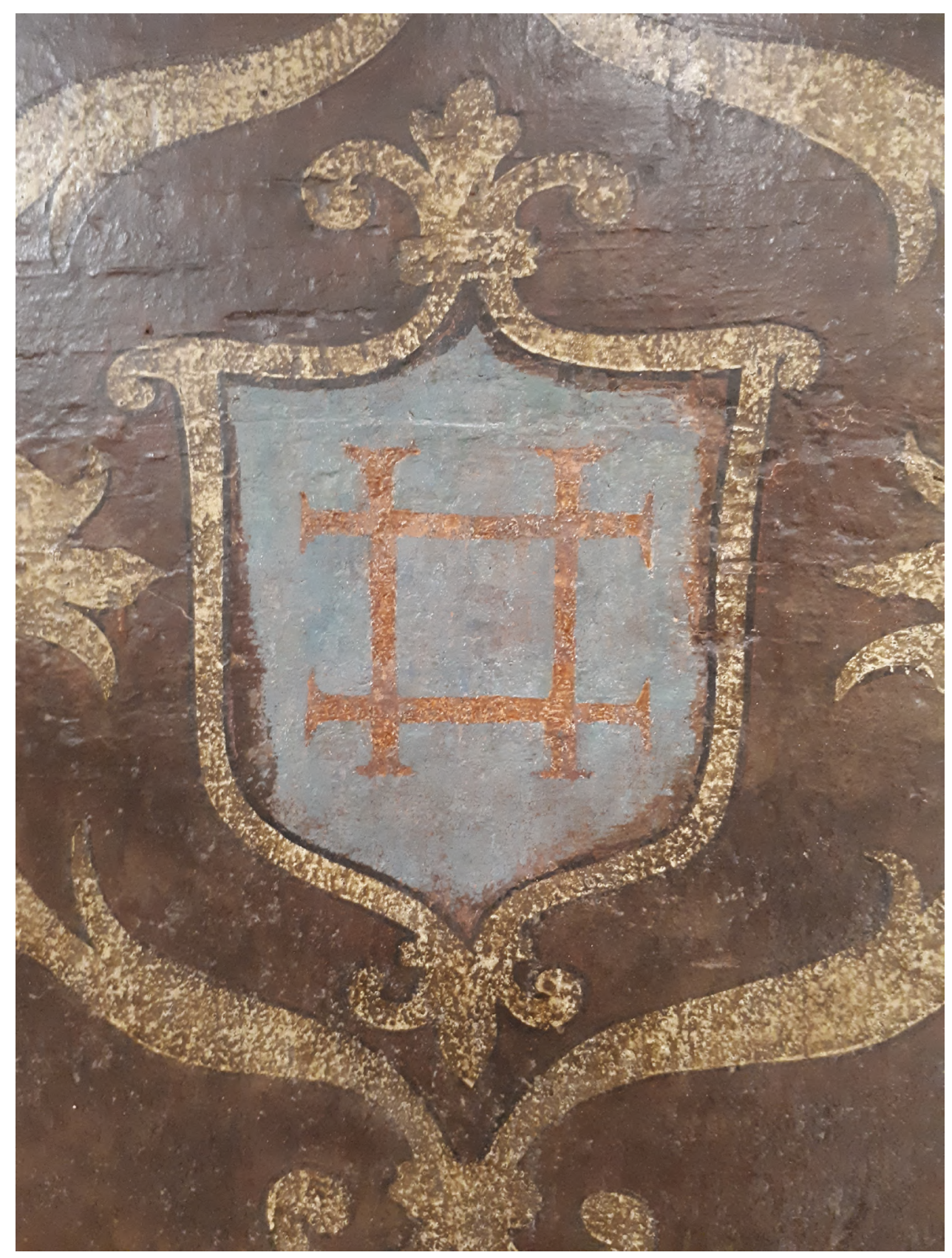

Foto 9: Vista de uno de los escudos heráldicos una vez recuperada la policromía original 
En la escena de la Anunciación se han conservado parcialmente algunas reintegraciones más antiguas que se ajustaban a la pintura original. De esta manera no se han perdido grandes zonas intervenidas anteriormente y solamente se han retocado para ajustarlas cromáticamente. Otras muchas zonas, previamente, se han tenido que nivelar con estuco tradicional, hecho con carbonato cálcico y cola de pieles Lebranc \& Bourgeois ${ }^{\circledR}$, para poder reintegrarlas.

Para la reintegración pictórica se ha utilizado acuarela Lebranc \& Bourgeois ${ }^{\circledR}$, siguiendo un sistema de presentación final básicamente ilusionista, aunque en algunas lagunas más grandes, se ha utilizado la técnica de retoque del tratteggio.

Como protección final se ha barnizado con resina de bajo peso molecular Laropal® A81.

Puntualmente, se ha ajustado la reintegración pictórica con pigmentos Gamblin ${ }^{\circledR}$, mezcla de pigmentos puros con resinas de bajo peso molecular.

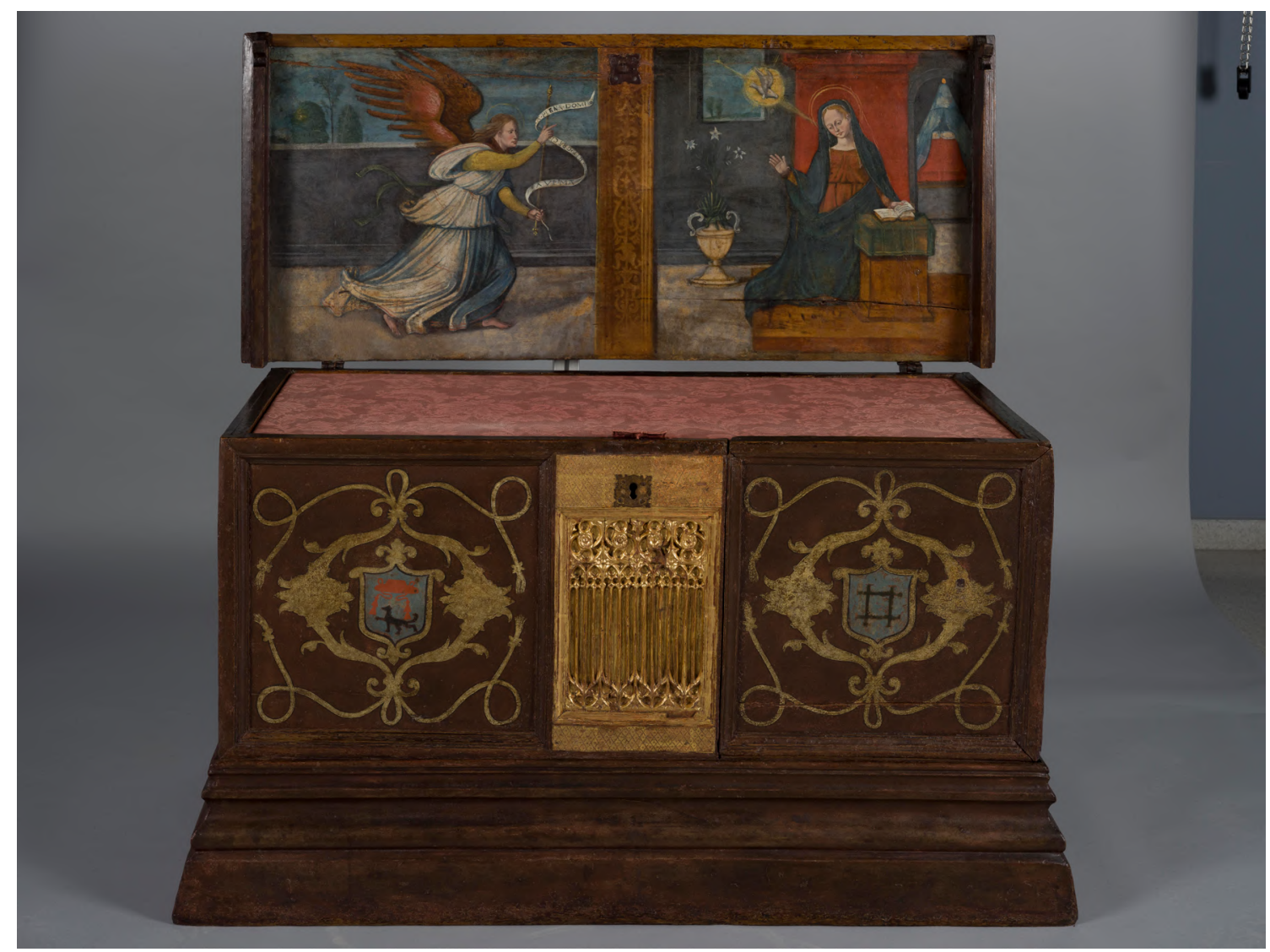

Foto 10: Vista general después de la intervención de conservación y restauración 


\section{NOTAS}

${ }^{1}$ Eva Pascual, "Arcas catalanas del siglo XVI: evolución de la tipología," en El moble del segle XVI: Moble per a l'edat moderna (Barcelona, Museu de les Arts Decoratives, Ajuntament de Barcelona, Associació per a l'estudi del moble, 2011), 95.

${ }^{2}$ Mònica Piera, “¿Dónde guardar? En arcas, armarios y cómodas,” en Historia y ciencia al servicio del estudio del mueble, Arcas policromadas y otros muebles del siglo XVI (Barcelona, Museu de les Arts Decoratives, Ajuntament de Barcelona, Associació per a l'estudi del moble, 2013), 17. ${ }^{3}$ Daniel Vilarrúbias, "Un arca nupcial de lujo del siglo XVI en el Museu Nacional," Blog Museu Nacional d'Art de Catalunya, 15 de octubre de 2020, https://blog.museunacional.cat/es/ una-arca-nuvial-de-lujo-del-siglo-xvi-en-el-museu-nacional/_

${ }^{4}$ Mercè Benavent et al., "Fitxa tècnica i estudi raonat de la caixa policromada amb l'Anunciació, Generalitat de Catalunya núm. inv. 227781," (Barcelona: Associació per a l'Estudi del Moble Gener, 2021), 11.

${ }^{5}$ Guadaira Macias et al., "Fitxa tècnica i estudi raonat de la caixa policromada amb l'Anunciació, Generalitat de Catalunya núm. inv. 227781," (Barcelona: Associació per a l'Estudi del Moble Gener, 2021), 20. 